\title{
Alternativa para diminuir as diferenças tecnológicas entre o Homo Zappiens e o Homo Papirus na Universidade Federal do Rio Grande do Sul
}

\author{
Magalí T. Longhi, Alexandre I. Gervini, Daniel T. de Oliveira \\ Hubert Ahlert, Jussara I. Musse \\ Centro de Processamento de Dados
}

Universidade Federal do Rio Grande do Sul, Av. Ramiro Barcelos, 2574, 90035-003, Porto Alegre, Rio Grande do Sul, Brasil magali@cpd.ufrgs.br, agervini@cpd.ufrgs.br, danielthomedcpd.ufrgs.br
hubert@cpd.ufrgs.br, jussara@cpd.ufrgs.br

Resumo. Este trabalho apresenta estudos desenvolvidos para compreender a relação entre a população Homo Papirus e Homo Zappiens da UFRGS e o uso de TIC encontradas nos processos de ensino e aprendizagem na modalidade presencial e a distância. A partir desta investigação, partiu-se para a elaboração de proposta apresentada à SEAD (Secretaria de Educação a Distância) como alternativa para conquistar o corpo docente do ensino presencial no uso das TIC e diminuir as diferenças tecnológicas entre o professor (não necessariamente um Homo Papirus) e aluno (nem sempre um Homo Zappiens) em disciplinas presenciais.

Palavras-chave. Homo Papirus, Homo Zappiens, Tecnologias de informação e comunicação, Educação presencial, Educação a distância.

\begin{abstract}
This article presents studies to understand the relationship between Homo Papirus and Homo Zappiens population at UFRGS and the institutionalized ICT to use in face-to-face and distance education. From this research, we prepared a proposal that was submitted to SEAD (Secretaria de Educação a Distância) as an alternative to develop a service to conquer teachers in face-to-face modality. We think that this service can help to reduce the technological differences between UFRGS teatchers (does not necessarily a Homo Papirus) and student (does not always a Homo Zappiens).
\end{abstract}

Keywords. Homo Papirus, Homo Zappiens, Information and communication technologies, Face-to-face education, Distance education.

\section{Introdução}

A palavra "tecnologia" tem diversas conotações de acordo com o contexto e a interpretação efetuada por grupos diversos e com propósitos divergentes. Pinto (2005) destaca que a tecnologia, no sentido popular, equivale à técnica, ou ao conjunto de procedimentos para chegar a um resultado nas mais diversas áreas do conhecimento; e, em sentido genérico, mede o avanço de um grupo social.

Segundo Castells (2005), a evolução histórica humana não é determinada pela tecnologia, mas contribui para transformar a sociedade. De fato, "a tecnologia é a sociedade, e a sociedade não pode ser entendida ou representada sem suas ferramentas tecnológicas." (CASTELLS, 2005, p. 25). 
Logo, em cada período histórico, instrumentos decisivos marcaram o avanço tecnológico de uma sociedade. Por exemplo, foi com a invenção da roda (6000 a.C.) que o Homo Sapiens transformou não apenas o modo de deslocamento como também a fabricação de outros mecanismos tecnológicos que vieram, entre outros campos, revolucionar a comunicação humana ${ }^{1}$. Nesse, em particular, a prensa móvel (inventada pelos chineses em 800 d.C. e adaptada por Gutenberg no final da Idade Média) possibilitou a divulgação de ideias em papel e a produção de cópias em volumes transportáveis como livros e jornais. É na era medieval que esses materiais passaram a fazer parte de escolas/universidades estruturadas de modo semelhante a que hoje se apresentam: presença de um professor que ensina a muitos alunos, muitas vezes, de diversas procedências.

Atualmente, uma revolução tecnológica, centrada no uso de tecnologias de informação e comunicação (TIC), está provocando mudanças significativas em vários setores da sociedade (CASTELLS, 2005). Em todos os níveis da educação, essas tecnologias vêm ampliando o espaço e tempo da sala de aula. Um novo cenário está se configurando, em que o professor "transmissor de informação, protagonista central das trocas entre seus alunos e guardião do currículo começa a entrar em crise" (COLL; MONEREO, 2010; p. 31)

Para fins de contexto histórico, este trabalho considera que a adoção da tecnologia de impressão em papel e o advento da internet contribuíram para a transformação da sociedade moderna, estabelecendo duas novas espécies do gênero Homo Sapiens: o Homo Papirus (como ora se sugere) e o Homo Zappiens (VEEN; VRAKKING, 2009) a ser discutido na seção 2.

Nesse sentido, a UFRGS, já algum tempo, vem discutindo a introdução das TIC em sala de aula. Depara-se com uma comunidade acadêmica formada, por um lado, pelo Homo Zappiens (que não se restringe aos discentes), ávido por tecnologia. Por outro, pelo Homo Papirus (não se incluindo apenas os docentes), confrontado pela necessidade de entender a virtualidade gerada pelas TIC.

Dessa forma, este trabalho tem por objetivo apresentar estudos desenvolvidos para compreender a relação entre a população Homo Papirus e Homo Zappiens da Universidade e o uso de TIC encontradas nos processos de ensino e aprendizagem na modalidade presencial e a distância. A partir desta investigação, partiu-se para a elaboração de proposta, apresentada à SEAD (Secretaria de Educação a Distância), como alternativa a para diminuir as diferenças tecnológicas entre o Homo Zappiens e o Homo Papirus em disciplinas presenciais.

A próxima seção define as espécies do Homo Sapiens. Tal definição é colocada como uma tentativa para explicar a dificuldade de implementar usos educacionais das TIC na Universidade. Cabe salientar que desde 2002, ano de criação da SEAD, recursos de EAD vem sendo disseminados institucionalmente. A seção 3 faz um breve relato da evolução tecnológica na UFRGS, enquanto que, na seção 4, contextualiza-se a comunidade acadêmica e os recursos de EAD por ela utilizados. Na seção 5 apresenta-se a proposta de desenvolvimento de serviço para uso isolado de recursos de EAD, em fase de incorporação no Portal de Serviços da Universidade (PSU). A seção 6 faz as considerações finais do trabalho.

\section{Homo Papirus x Homo Zappiens}

As diferenças entre o Homo Zappiens e o Homo Papirus são vistas, neste trabalho, na maneira como as espécies do Homo Sapiens lidam com a informação e resolvem problemas. A primeira tem uma postura não-linear para dominar o fluxo de informação. Os 
problemas são solucionados interagindo simultaneamente com múltiplas tarefas, acessando vários canais de informação em que mais de um sentido humano está envolvido. Para o Homo Zappiens não existem fronteiras de espaço e de tempo. Já a segunda, nascida em época analógica ou criada na analógica-digital, geralmente resolve os problemas um de cada vez e adota uma abordagem sequencial para buscar informações (por exemplo, a leitura de um livro é feito do início ao fim).

O Homo Papirus é reconhecido como aquele que aprendeu a usar o papel (nos mais diversos formatos: panfletos, livros, jornais, blocos, etc.) e superfícies reusáveis (quadronegro, quadro-branco, flipchart, etc.) associadas a outros instrumentos (lápis, caneta, giz, apagador, etc.) de modo a registrar suas ideias e a apoiar o ensino e a aprendizagem do conteúdo neles expressos.

$\mathrm{Na}$ era digital, ele é retratado pelos colonizadores (PALFREY; GASSER, 2011) e imigrantes digitais (PRENSKY, 2001). Os colonizadores digitais são os representantes do mundo analógico; isto é, ainda se baseiam nas formas tradicionais de interação, embora tenham ajudado a dar contorno ao universo da cultura digital. Os imigrantes digitais interagem por meio de ferramentas tecnológicas relacionadas à internet, mas não se desligam do mundo analógico (por exemplo: preferem ler em papel impresso).

O Homo Papirus pode vir a ter fluência tecnológica (RESNICK, 2002) se possuir a capacidade de reformular conhecimentos, expressar-se criativa e apropriadamente, bem como produzir e gerar informação por meio de tecnologias digitais. A fluência tecnológica está associada à "alfabetização digital", termo geralmente utilizado para "designar o conjunto de conhecimentos, habilidades e competências necessários para um uso funcional e construtivo das TIC" (COLL; ILLERA, 2010; p. 289).

Ocorre que a utilização das TIC para produzir leitura ou escrita, difundir textos e enviar mensagens não tornam o Homo Papirus fluente tecnologicamente. As TIC incorrem em práticas que não incluem apenas a linguagem escrita, mas também as visual, auditiva e audiovisual. De fato, a ubiquidade das TIC e a capacidade de processar sons e imagens, produzir e exibir vídeos, construir e operar em ambientes virtuais 3D, além da escrita, conferem "uma centralidade e um protagonismo sem precedentes" (COLL; ILLERA, 2010; p. 297). De qualquer modo, as propriedades das TIC (acessibilidade, usabilidade, adaptabilidade, mobilidade e cooperação) promovem um ensino inclusivo, uma educação não formal e informal e uma aprendizagem colaborativa e cooperativa que devem ser consideradas.

O Homo Zappiens (VEEN; VRAKKING, 2009) atua em uma "cultura cibernética", iniciada na segunda metade do século XX, quando o programa BBS (Bulletin Board System) permitiu às pessoas interagirem através de seus computadores, conectados por linha telefônica. Desde então, a invenção, o aperfeiçoamento e a adoção das TIC vem transformando profundamente as relações da sociedade contemporânea. Pode ser definido como um nativo digital (PRENSKY, 2001), isto é, aquele que nasceu em tempos de Internet (após 1980) e que tem acesso às tecnologias digitais nela disponibilizadas. Desenvolveu estratégias para se comunicar, cooperar e lidar com a informação, habilidades essas mediadas por todo tipo de tecnologia digital, móvel ou não móvel. A tecnologia é, portanto, totalmente incorporada no seu quotidiano, participando de comunidades virtuais ou "zapeando" pelas informações.

O trabalho desenvolvido por Oblinger e Oblinger (2005), na educação superior dos Estados Unidos, revela que o Homo Zappiens é:

1. Digitalmente alfabetizado, isto é, tem habilidade em usar diferentes TIC e navega pela internet de maneira intuitiva. 
2. Conectado, independentemente do dispositivo utilizado (computador de mesa, portátil ou de comunicação móvel), ele está sempre conectado.

3. Imediatista, pois tende a ser simples na maneira de proceder via TIC e valoriza mais a velocidade do que a acurácia ao enviar e receber informação.

4. Empírico ou prefere aprender fazendo em vez de ser ensinado sobre como fazer.

5. Social, já que é um grande comunicador e gravita em torno de atividades que promovam e reforçam a interação social.

6. Orientado à abordagem peer-to-peer, ou seja, privilegia a aprendizagem entre pares. Prefere acreditar no seu par, mais do que no formador, para aquilo que deve prestar atenção.

7. Orientado a resultados, isto é, não é dado a ambiguidades ou a tarefas sem clareza. Gosta que o formador seja claro na estrutura de como atingir o objetivo.

8. Orientado à descoberta indutiva, a formular hipóteses e a descobrir regras porque anseia por interatividade e experimentação. Facilmente se desinteressa se a sala de aula não é interativa ou lenta.

9. Visual e cinestésico. Recusa-se a ler grandes quantidades de texto. Sente-se mais confortável com imagens, vídeos e/ou interagindo com a informação.

10. Orientado a desafios, visto que prefere coisas que têm importância, que possa ser desafiado a tomar parte de atividades comunitárias. Acredita que a ciência e a tecnologia devem ser usadas para resolver problemas complexos.

Nessa perspectiva, percebe-se uma encruzilhada de influências ao se tratar de tecnologia, sociedade e educação (COLL; MONEREO, 2010). O Homo Sapiens está diante de um novo cenário. As suas duas espécies convivem em uma educação que insiste no padrão tradicional de ensino e aprendizagem, configurada por uma estrutura hierarquizada, em que a linearidade e a não colaboração são privilegiadas. Contudo, o Homo Zappiens está reconfigurando a educação e, por sua vez, o trabalho docente. As "novas tecnologias" (TIC) começaram a ser referência nos discursos pedagógicos. Algumas vezes como alternativa para solucionar problemas educacionais, outras vezes como substituição às "velhas tecnologias" (quadro-negro, giz, livro, etc.).

De qualquer forma, o impacto das TIC na educação está relacionado com as mudanças que elas introduziram na sociedade (nova forma de organização econômica, social, política e cultural). De fato, conforme salientam Coll e Monereo (2010), as TIC admitem "novas maneiras de trabalhar, de comunicar-se, de relacionar-se, de aprender, de pensar e, em suma, de viver" (p.15). O educador precisa reinventar-se, reformar-se pois o aluno "não é mais uma tabula rasa a ser escrita pelo professor" (BUARQUE, 2012; p.145). Da mesma forma que não se imaginava um professor sem giz e quadro-negro no século passado, neste não se concebe um professor que não faça uso das TIC ou que não se adapte à evolução de novos equipamentos pedagógicos (Buarque, 2012).

\section{A evolução das TIC na UFRGS}

A evolução tecnológica na UFRGS, no que tange aos processos de ensino e aprendizagem, tem início na primeira metade dos anos 80. Em consonância com o desenvolvimento mundial de microcomputadores, o projeto da Universidade "Aplicações em Microcomputadores" teve como resultado o desenvolvimento do software SISCAI para o projeto EDUCOM do Governo Federal, com aplicação em alunos de pós-graduação em Educação. Mais tarde, o aplicativo sofreu reformulações e passou a denominar-se CAIMI, com aplicação no ensino do $2^{\circ}$ grau. 
No final dos anos 80, início dos 90, a UFRGS foi a primeira instituição do país a criar um curso de especialização em Informática na Educação. Ao mesmo tempo, os serviços de correio eletrônico e de transferência de arquivos entre os campi, como também a ligação com a internet foi viabilizado pelo Centro de Processamento de Dados (CPD). Tal iniciativa possibilitou à UFRGS desenvolver o primeiro projeto de Educação a Distância (EAD) por meio de Packet-Radio, na frequência de radioamador, alcançando alunos e professores de classes de alfabetização, incluindo a alfabetização de deficientes auditivos ${ }^{3}$.

Do mesmo modo, a instalação da rede de comunicação de dados permitiu, em 1995, a implementação do projeto "Levando a Universidade à Aprendizagem Remota" (LUAR). O LUAR investia na educação continuada, preparando professores no uso das tecnologias digitais, a partir de ambientes de aprendizagem em rede com acesso assíncrono ${ }^{3}$.

Importante salientar que, na segunda metade dos anos 90, o CPD executou ações que promoveram a informatização da área acadêmica e o acesso facilitado das informações através do Portal de Serviços da Universidade (PSU). Desse modo, a disponibilização de TIC direcionadas à qualificação dos processos de ensino, pesquisa e extensão, como também à modernização da gestão acadêmica, tornou a UFRGS referência para outras instituições.

A partir de 1998, com o intuito de compartilhar experiências e debater sobre EAD, foi criado o Fórum EAD que culminou com a necessidade de se institucionalizar a EAD na UFRGS. Dessa maneira, foi sugerida à Administração Central a adoção de um ambiente virtual de aprendizagem (AVA) ${ }^{4}$ para a EAD institucional (fosse ela desenvolvida na Instituição ou adquirida) e a criação da Secretaria de Educação a Distância (SEAD) para articular as ações de EAD nos diversos níveis: ensino, pesquisa e extensão.

A UFRGS, através da SEAD, mantém três AVA institucionais: MOODLE, NAVi e ROODA, que são suportados pelo CPD e estão em sincronia com o Sistema de Controle Acadêmico (SCA) da Universidade.

O NAVi (Núcleo de Aprendizagem VIrtual) ${ }^{5}$, precursor na disponibilização de disciplinas via web (em 1998) na Universidade, foi desenvolvido com o objetivo de consolidar ferramentas de apoio a aulas presenciais, bem como o de apoiar os cursos de graduação, pós-graduação e extensão na modalidade a distância da Escola de Administração. Em 2006, o ambiente sofreu reformulações com enfoque sistêmico. Voltado à comunidade UFRGS, passou também a apoiar programas governamentais, no âmbito do Ministério da Saúde, do Ministério do Desenvolvimento Social, da Universidade Aberta do Brasil (UAB) e do Banco do Brasil.

O ROODA (Rede cOOperativa De Aprendizagem) ${ }^{6}$ é um AVA desenvolvido pelo Núcleo de Tecnologias Digitais aplicadas à Educação (NUTED), ligado à Faculdade de Educação. A construção da plataforma (iniciada em 2000) foi fundamentada em princípios construtivistas, tendo implícita a concepção epistemológica interacionista (embora possa ser utilizada para uma aprendizagem com foco transmissionista), valorizando, dessa forma, o processo de interação e cooperação entre os participantes. O ROODA, reconhecido pela UFRGS em 2003, passou integrar o projeto de EAD da instituição.

A institucionalização das duas plataformas significou a integração parcial ao SCA e a realização de testes de satisfação e de adequação técnica. Mais tarde, tendo em vista as perspectivas de ampliação de projetos no âmbito da UAB e as orientações do Ministério da Educação para padronizar o AVA a ser utilizado em seus cursos e nos da Rede Gaúcha de Educação a Distância (REGESD), a UFRGS, em 2007, adota uma terceira plataforma (NITZKE; GRAVINA; CARNEIRO, 2008): o MOODLE (Modular Object-Oriented Dynamic Learning Environment) ${ }^{7}$. 
Desde então, a UFRGS, através da SEAD, vem organizando, capacitando e fomentado condições para o desenvolvimento e a implementação de atividades de EAD a partir dos três AVA (seja para a modalidade a distância, seja para disciplinas e cursos presenciais).

\section{Configuração da comunidade acadêmica e os recursos de EAD}

O ensino é um trabalho interativo (TARDIF; LESSARD, 2008). Se todo trabalho pressupõe a presença de uma tecnologia, então, em tempos do Homo Zappiens, o AVA é uma das tecnologias que pode redimensionar a interação entre docentes e alunos. Nele, a interação é fomentada pelos recursos de comunicação síncrona e assíncrona, que explicam a criação de comunidades virtuais de aprendizagem com ações mais colaborativas e cooperativas.

Os AVA são concebidos a partir de pressupostos acerca do processo de ensino e aprendizagem. Podem tanto estar voltado para propósitos específicos quanto centrado no usuário ou no curso (BEHAR, 2009). Contudo, em se tratando de modalidade presencial, o professor, ao escolher um ambiente para apoio a sua disciplina, nem sempre leva em consideração tais aspectos. Usualmente, a escolha é direcionada pelas informações que o docente obtém a partir da capacitação efetuada, por indicação do Departamento ou, ainda, de colegas.

$\mathrm{Na}$ UFRGS, as disciplinas/turmas ativas em um semestre (ministradas na modalidade presencial, semi-presencial ${ }^{8}$ e a distância em nível de graduação e pósgraduação stricto sensu) são da ordem de 5400. Dados relativos aos anos 2010 e $2011^{9}$, demonstram que a média de turmas que empregam AVA é de 30,37\%, apresentando um crescimento médio semestral em torno de $6 \%$.

A distribuição de uso dos AVA institucionalizados no período 2010-2011 está ilustrada na Figura 1. O gráfico aponta que o MOODLE é mais utilizado. Em parte, porque é o mais conhecido nas diversas áreas (tem difusão e suporte mundial), com várias edições de capacitação. Já o NAVi e ROODA são mais utilizados nas áreas de Ciências Sociais e de Ciências Humanas.

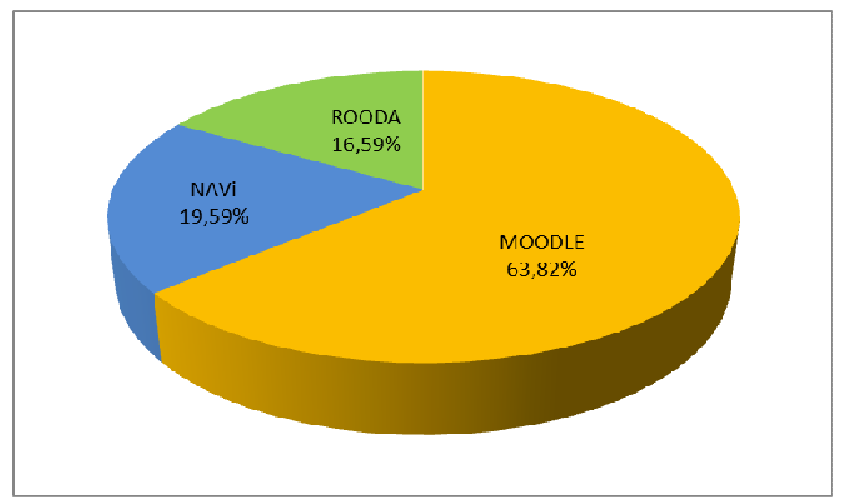

Fig. 1. Distribuição do uso dos AVA em 2010 e 2011

Destaca-se que, no semestre 2011/2, a UFRGS somou 2755 professores ativos. O perfil etário do corpo docente da Universidade é ilustrado na Figura 2. Observa-se que 99,96\% da população docente, embora atuante em era digital, é apontado como Homo Papirus. Dos 2755 professores ativos, 37,20\% solicitaram, em 2011/2, o uso de plataforma para suportar suas disciplinas/turmas de graduação e/ou pós-graduação stricto sensu em todas as modalidades de ensino. Tal porcentagem mostra que, aos poucos, as tecnologias vêm sendo introduzidas na sala de aula. 


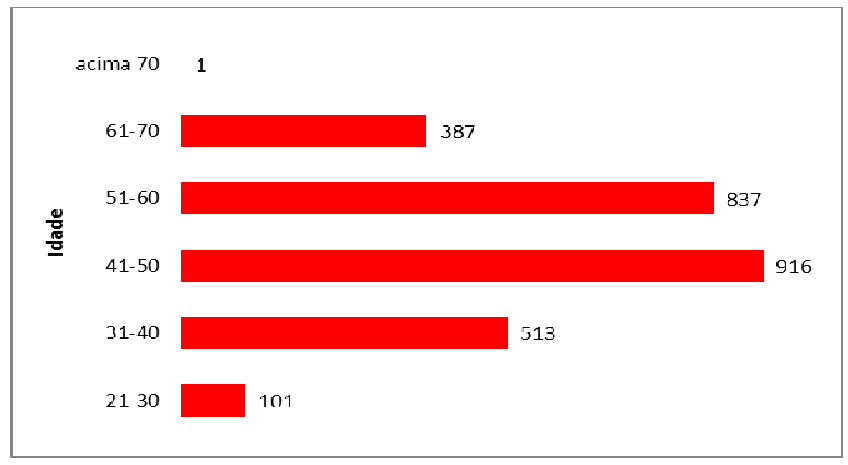

Fig. 2. Perfil etário dos professores da UFRGS

Por outro lado, a Figura 3 revela a distribuição dos alunos de graduação matriculados no semestre $2011 / 2$ por faixa etária. Do corpo discente da graduação constatase que $82,70 \%$ (faixa dos 15 aos 30 anos) possuem as características Homo Zappiens.

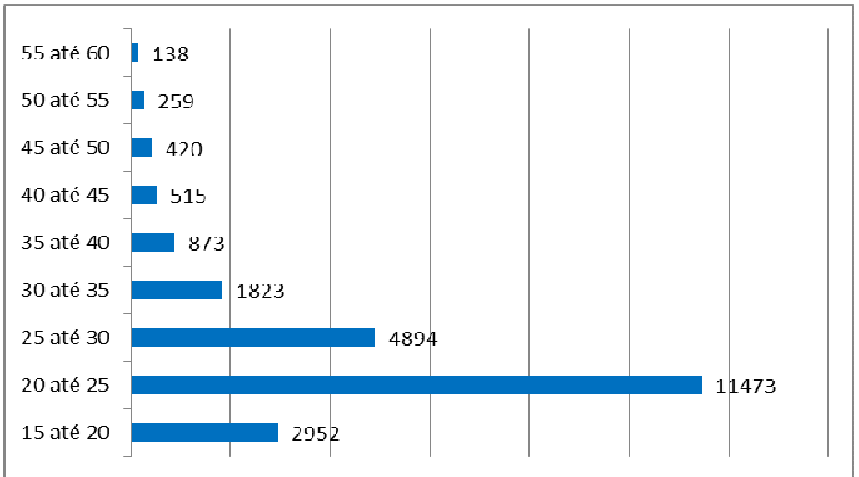

Fig. 3. Número de alunos matriculados na graduação em 2011/2 por faixa etária

Considerando-se que a Universidade disponibiliza diversas oportunidades para facilitar a aprendizagem, e que a utilização de tecnologias centradas no aluno propicia a construção de conhecimento (CHRISTENSEN; HORN; JOHNSON, 2009) parte-se, então, para a questão norteadora deste trabalho: como ampliar os recursos de EAD com o intuito de diminuir a lacuna entre docentes e discentes (cada um com suas características Homo Papirus ou Homo Zappiens), de modo a facilitar a interação e a cooperação nas atividades de ensino presencial?

Apresentar recursos de comunicação, de disponibilização de conteúdos e de administração das atividades de ensino favorece os processos de interação, colaboração e de cooperação entre os participantes de cursos presenciais (COLL; MONEREO, 2010; BEHAR, 2009). Entende-se que a solução de integrar essas potencialidades ao portal de serviços do aluno e do docente, pode contribuir para diminuir o descompasso entre o Homo Papirus e Homo Zappiens da Universidade.

\section{O projeto UFRGS Virtual}

Os AVA institucionalizados na UFRGS (MOODLE, NAVi e ROODA) são LMS (Learning Manegments System) ou softwares desenvolvidos com base em um (ou mais de um) pressuposto pedagógico. Também são conhecidos por plataformas EAD por empregarem principalmente uma infra-estrutura tecnológica para atender aos objetivos pedagógicos. Nem sempre esses recursos estão em consonância com os processos e eventos da instituição (por exemplo, matrícula de alunos, atribuição de conceitos, distribuição de disciplinas/turmas, etc.). 
Verifica-se, por um lado, que a comunidade acadêmica de atuação exclusiva na modalidade presencial ainda não faz amplo uso dessas plataformas e, por extensão, dos recursos tecnológicos por elas disponibilizados. Por outro, a cada nova versão ou atualização dessas plataformas, há a necessidade de reinstalação e de modificação das rotinas de sincronização dos diversos processos da Universidade neles acoplados.

Assim, com o intuito de difundir a infraestrutura tecnológica encontrada nas plataformas EAD para a comunidade acadêmica que atua na modalidade presencial, a UFRGS iniciou em 2011 o projeto UFRGS Virtual ${ }^{10}$. O projeto abrange estudo e desenvolvimento de ações para fomentar o uso de TIC nos cursos de graduação e pósgraduação. Nele estão contemplados os subprojetos "Sala de Aula Virtual" e "Repositório de materiais educacionais abertos".

Neste trabalho, apresenta-se a proposta de desenvolvimento da Sala de Aula Virtual, que vem a ser um serviço integrado ao portal do aluno e do professor com a finalidade de ampliar o uso de TIC para apoio às atividades de ensino presencial. As tecnologias estão sendo desenvolvidas pelo CPD, com apoio da SEAD.

A Sala de Aula Virtual é um ambiente que agrega alguns dos serviços já disponibilizados no Portal do aluno e docente e implementa alguns dos recursos de EAD com o intuito de experimentação. A ideia é ser um ambiente propulsor para que o corpo docente (e discente) saia da "idade do papel". Destaca-se que a construção da Sala de Aula Virtual não vem substituir os AVA institucionalizados, tampouco, ser mais um. O ambiente Sala de Aula Virtual não é um AVA, pois não está fundamentado em um princípio pedagógico específico como o são as outras plataformas institucionalizadas. Contudo, tem a vantagem de estar totalmente integrado ao Sistema de Controle Acadêmico e prescinde o uso de rotinas de sincronização para suportar processos administrativos.

O acesso à Sala de Aula Virtual é feito pelo portal (PSU) através da autenticação do usuário pelo tipo de vínculo (aluno ou professor) que possui com a instituição. Em sua primeira versão, a interface está configurada para os vínculos: aluno de graduação e de pósgraduação stricto sensu, professor de graduação e de pós-graduação stricto sensu.

A Figura 4 ilustra através de um mapa conceitual o projeto em discussão. $\mathrm{O}$ ambiente é orientado ao usuário e às atividades de ensino mais atuais (do tipo presente, na figura). Uma atividade de ensino atual pode ser uma disciplina do período letivo vigente ou a última desenvolvida antes da desativação do usuário do curso (por diplomação, por aposentadoria, ou outro tipo de evasão). Todas as informações e ferramentas utilizadas nas atividades antigas são apresentadas por solicitação do usuário. Nas atividades de ensino futura, o professor poderá configurar as funcionalidades antes do período letivo iniciar.

Neste momento, o ambiente está em desenvolvimento, com algumas funcionalidades em produção, tais como: atividades de ensino regulares (presente, passado e futuro) ministradas/cursadas; informações gerais da atividade de ensino, como súmula, platoforma EAD e seu direcionamento, método de avaliação e bibliografia; participantes, correio eletrônico e Fórum.

\section{Considerações Finais}

A UFRGS vem perseguindo uma mudança paradigmática de modelo educacional que privilegie a cultura da aprendizagem. Recorrer ao AVA demanda esforços redobrados do professor, inclusive o de como lidar com suas funcionalidades. O professor precisa se descentralizar para reestruturar seu novo papel e descobrir meios que o habilitem a gerenciar a aprendizagem de um novo perfil de aluno. 


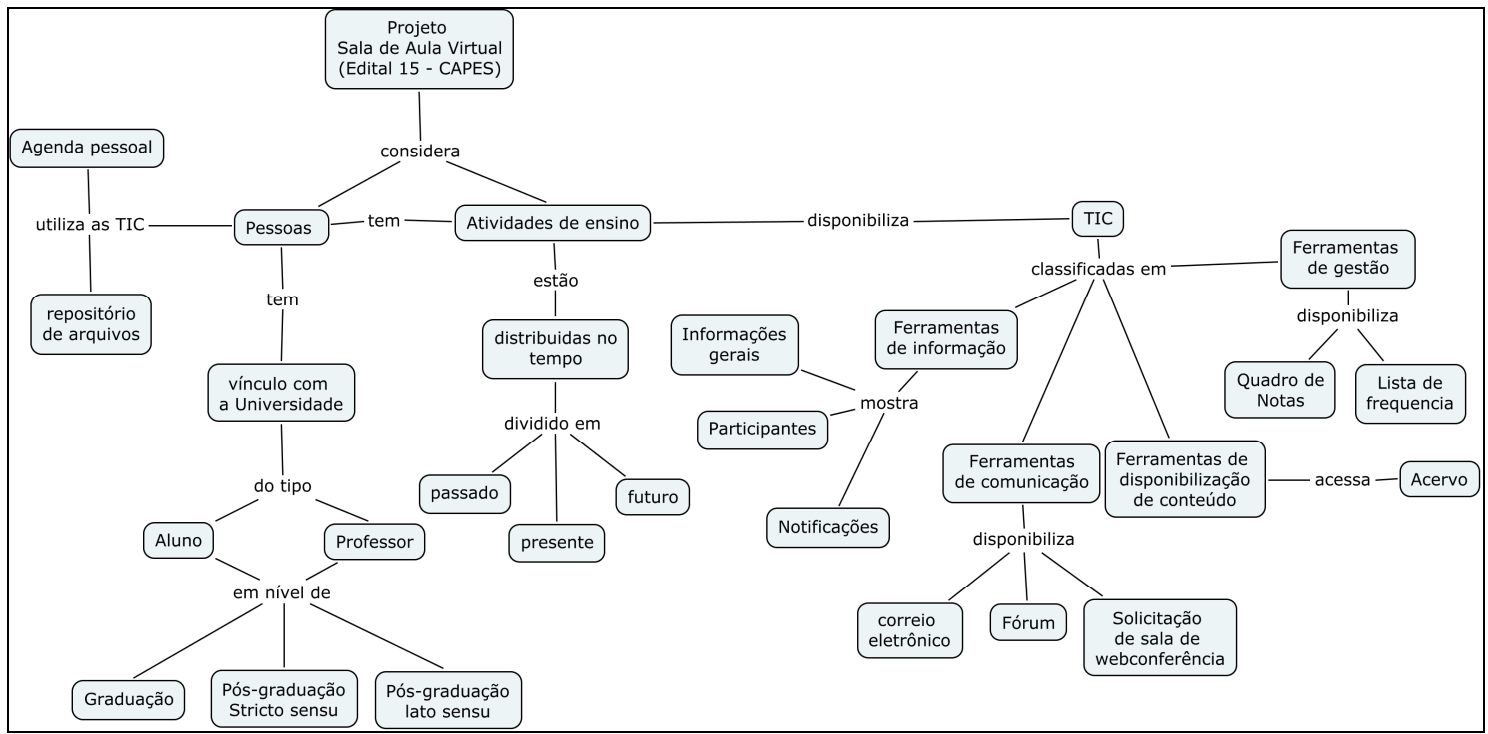

Fig. 4. Mapa conceitual geral do projeto Sala de Aula Virtual

Observa-se que muitos professores utilizam TIC de fácil uso espalhados pela internet (por exemplo, blogs, editores de textos colaborativos, construtores de sites, repositórios de mídias, etc.) sem a preocupação de que as informações geradas, produtos da Universidade, são colocadas em domínio público.

Diante desse reconhecimento, partiu-se, então, para o estudo e a implementação de determinados recursos EAD no portal da UFRGS. Para tanto, teve-se em conta: (1) as potencialidades das TIC implementadas nas plataformas EAD; (2) a baixa adesão às plataformas no que tange ao apoio às atividades de ensino presencial; e (3) que, mesmo quando utilizadas nessa modalidade, essas plataformas servem, essencialmente, como repositório de materiais educacionais.

Em síntese, o objetivo deste artigo foi o de chamar a atenção para uma alternativa que, atendendo ao princípio da plena integração com o SCA e PSU, se contraponham ao uso do AVA apenas como um repositório de materiais. Trata-se de, por meio das TIC, estimular atividades que promovam a qualidade do ensino e da aprendizagem, ao se estreitar o hiato entre usuários Homo Zappiens e Homo Papirus. Em outros termos, conquistar o docente do ensino presencial para a adoção de tecnologias típicas da EAD, de tal modo que ele possa, com mais segurança, selecionar, dentre os três AVA consagrados na Universidade, aquele que considerar mais adequado.

\section{Agradecimentos}

Os autores desejam agradecer a equipe de desenvolvimento da Divisão de Sistemas de Ensino e da Divisão de Administração de Dados do CPD. Nossos agradecimentos à SEAD por oportunizar ideias, recursos tecnológico e humano ao desenvolvimento do Sala de Aula Virtual como também presença nas discussões pedagógicas, bem como na análise de requisitos e de testes do ambiente. Nosso especial reconhecimento a todos os alunos e professores que apontaram sugestões, críticas e erros no ambiente que ora está em produção, na sua primeira versão.

\footnotetext{
Notas

${ }^{1}$ Nesse tempo, o Homo Sapiens já grafava sua vida cotidiana em diversas superfícies (rochas, ossos, tabuletas de barro, tecidos e materiais fibrosos como papiros e pergaminhos).

2 Zapear é o processo de mudar o fluxo de informação para outro, aumentando a densidade de informações no menor tempo possível (VEEN; VRAKKING, 2009).

${ }^{3}$ Informações extraídas em “Webfólio da EAD”. Disponível em http://www.pgie.ufrgs.br/webfolioead.
} 
${ }^{4}$ Um ambiente virtual de aprendizagem (AVA) pode ser definido como um espaço virtual formado pelos sujeitos participantes (aluno, professor e tutor) e materiais de ensino e de aprendizagem nele contidos; pelas interações que ocorrem e relações que se formam; e pelas formas de comunicação disponibilizadas para as trocas de informações. Este espaço virtual é muitas vezes conhecido sob a designação de plataforma (Behar, 2009).

${ }^{5}$ Disponível em https://www.ead.ufrgs.br/navi

${ }^{6}$ Disponível em https://www.ead.ufrgs.br/rooda

${ }^{7}$ O MOODLE, seguindo a filosofia de software livre, foi desenvolvido na Austrália e é utilizado por mais de 66.000 websites em 218 países (dados extraídos em Fevereiro de 2012 em http://moodle.org/sites)

${ }^{8}$ Também conhecidas como "20\% a distância".

${ }^{9}$ Em anos anteriores, os professores não escolhiam um AVA específico. Ao solicitar o uso de uma dessas ferramentas de apoio, efetuava-se a sincronização dos dados nos três AVA simultaneamente, o que impediu uma análise aprofundada das preferências dos professores quanto aos ambientes.

${ }^{10}$ O projeto UFRGS Virtual está sendo financiado pela CAPES (Edital no 15) sob o título "Proposta para o Fomento ao Uso de Tecnologias de Comunicação e Informação nos Cursos de Graduação da UFRGS”.

\section{Referências}

BEHAR, PA: Modelos Pedagógicos em Educação a Distância. Artmed, Porto Alegre (2009)

BUARQUE, C.: Formação e invenção do professor no século XXI. En: Litto, FM, Formiga, M. (eds), pp. 145 a 147. 2. ed. Pearson, São Paulo (2012)

CASTELlS, M.: A sociedade em rede. 8. ed. São Paulo: Paz E Terra, 2005. (A era da Informação: economia, sociedade e cultura; volume I).

CHRISTENSEN, C.; HORN, M.; JOHNSON, C.: Inovação na sala de aula: como a inovação de ruptura muda a forma de aprender. Artmed, Porto Alegre (2009)

COLL, C., MONEREO, C.: Educação e aprendizagem no século XXI: novas ferramentas, novos cenários, novas finalidades. In: Coll, C., Monereo, C. (eds), Psicologia da Educação Virtual. pp. 15 a 46. Artmed, Porto Alegre (2010)

COLL, C., ILLERA, J.L.R.: Alfabetização, novas alfabetizações e alfabetização digital: as TIC no currículo escolar. In: Coll, C., Monereo, C. (eds), Psicologia da Educação Virtual. pp. 289 a 310. Artmed, Porto Alegre (2010)

NITZKE, J.A.; GRAVINA, M.A.; CARNEIRO, M.L.F.: O percurso e a institucionalização da EAD na UFRGS. En: V ESUD Congresso Brasileiro de Ensino Superior a Distância. Anais do V ESUD, UNIREDE, Brasília (2008)

OBLINGER, D.; OBLINGER, J.: Educating the Net generation. Boulder: Educase, 2005.

PALFREY, J.; GASSER, U.: Nascidos na era digital: entendendo a primeira geração de nativos digitais. Artmed, Porto Alegre (2011)

PINTO, A.V.: O conceito de tecnologia. Volume I. Contraponto, Rio de Janeiro (2005)

PRENSKY, M.: Digital natives, digital immigrants. On the Horizon, MCB University Press, vol.9, n.5 (2001)

RESNICK, M. Rethinking Learning in the Digital Age. In The Global Information Technology Report: Readiness for the Networked World, edited by G. Kirkman. Oxford University Press. (2002).

TARDIF, M., LESSARD, C.: O trabalho docente: elementos para uma teoria da docência como profissão de interações humanas. 4.ed. Vozes, Petrópolis, RJ (2008)

VEEN, W.; VRAKKING, B.: Homo Zappiens: educando na era digital. Artmed, Porto Alegre (2009) 